Sādhanā Vol. 36, Part 2, April 2011, pp. 193-208. (C) Indian Academy of Sciences

\title{
Influence of interface properties on fracture behaviour of concrete
}

\author{
G APPA RAO ${ }^{1, *}$ and RAGHU PRASAD B K ${ }^{2}$ \\ ${ }^{1}$ Department of Civil Engineering, Indian Institute of Technology Madras, \\ Chennai 600 036, India \\ ${ }^{2}$ Department of Civil Engineering, Indian Institute of Science, \\ Bangalore 560 012, India \\ Present address: University of Stuttgart, Pfaffenwaldring 4, \\ Stuttgart 70569, Germany \\ e-mail: garao@iitm.ac.in
}

MS received 4 June 2009; revised 2 December 2010; accepted 11 December 2010

\begin{abstract}
Hardened concrete is a three-phase composite consisting of cement paste, aggregate and interface between cement paste and aggregate. The interface in concrete plays a key role on the overall performance of concrete. The interface properties such as deformation, strength, fracture energy, stress intensity and its influence on stiffness and ductility of concrete have been investigated. The effect of composition of cement, surface characteristics of aggregate and type of loading have been studied. The load-deflection response is linear showing that the linear elastic fracture mechanics (LEFM) is applicable to characterize interface. The crack deformation increases with large rough aggregate surfaces. The strength of interface increases with the richness of concrete mix. The interface fracture energy increases as the roughness of the aggregate surface increases. The interface energy under mode II loading increases with the orientation of aggregate surface with the direction of loading. The chemical reaction between smooth aggregate surface and the cement paste seems to improve the interface energy. The ductility of concrete decreases as the surface area of the strong interface increases. The fracture toughness (stress intensity factor) of the interface seems to be very low, compared with hardened cement paste, mortar and concrete.
\end{abstract}

Keywords. Interface; concrete; bond strength; fracture toughness; stiffness; ductility.

\section{Introduction}

The hardened concrete is a multiphase composite consisting of cement paste, aggregate and interface between cement paste and aggregate. The interface is a thin layer of cementitious

*For correspondence 
by-products formed around the aggregate surface. The microstructure, crack resistance and fracture toughness of interface are important parameters to understand the behaviour of concrete. The crack formation and micro-crack growth at the interface influence the strength and fracture toughness. The load transfer mechanism between these phases depends on the type of cement paste, surface characteristics of aggregate and adhesive bond developed at the interface. Smaller thickness of interface in cementitious composites tends to transfer the stresses from the bulk paste to the aggregate efficiently. This increases the participation of the coarse aggregate for resisting the applied loads. The cracks formed in the bulk paste may propagate along the weak interface or may cross the aggregate with strong interface. In high strength cementitious materials, the interface is known to be strong; thus leading to transgranular type of failure. This can lead to high strength composite with low deformation at the peak loads.

\section{Review of literature}

Concrete as a two-phase composite consists of mortar matrix and aggregate. The elastic mismatch between the mortar and the coarse aggregate can cause stress concentration at the interface. The interface micro-structure and its pore size distribution have been observed to be similar to that of the plain cement pastes (Winslow \& Liu 1990). In mortars and concretes, the cement paste contains more porous microstructure. The addition of silica fume alters the pore structure in to more discontinuous and impermeable. The pore structure in the interface gets altered by the continuous hydration of $\mathrm{Ca}(\mathrm{OH})_{2}$ on aggregate surfaces (Cheng-yi \& Feldman 1985; Feldman 1986; Zimbelmann 1987).

The water filled gaps are formed around the aggregates due to bleeding. Due to the wall effect, gaps are filled with cement hydration products in the interface zone. The interface is developed as a layer of $\mathrm{CH}$ film, over which another layer of $\mathrm{CSH}$ products forming a composite or 'duplex' film on the aggregate surface. This duplex film binds the bulk paste by the growth of large $\mathrm{CH}$ crystals as the hydration of cement continues. The thickness of the interface decreases with the addition of silica fume, which tends to affect the pattern of crystallization and degree of orientation of $\mathrm{CH}$ at the aggregate surface during early hydration (Larbi \& Bijen 1990; Chengyi \& Feldman 1985). The addition of $8 \%$ silica fume affects the tensile strength (Toutanji et al 1999). The interface energy $(\gamma)$ is the work done against the surface attractions. For example, the work done against breaking a gelatine-glass interface is about $0.071 \mathrm{~J} / \mathrm{m}^{2}$, which is sufficient to characterize the van der Waal's forces of attractions. The bond strength between the cement paste and the aggregate increases when the aggregate surface is covered with a suspension of pumice, detergent and water glass (Zimbelmann 1987).

The thickness of the interface ranges between $20 \mu \mathrm{m}$ and $50 \mu \mathrm{m}$ from the aggregate surface with a massive $\mathrm{Ca}(\mathrm{OH})_{2}$ layer engulfing the aggregate and also by some channel-type gaps (Bentur \& Cohen 1987). At the age of 90 days, the addition of fly ash increases the interface bond strength and fracture toughness due to the pozzolanic action (Wong et al 1999), whereas the interface bond strength and fracture toughness decrease at 28 days with 45 and $55 \%$ fly ash. The surface effects are produced by the aggregate surface due to high water-cement ratio at the interface (Monterio et al 1985). The extra water allows the ions to diffuse easily and eliminates the geometrical constraints in the bulk paste, which results in high porosity and formation of large CH crystals and ettringite in the interface (Ping \& Beaudoin 1992; Cohen et al 1994). The strength of the interface with pretreated quartz aggregate is higher than that of the normal quartz aggregates (Yang et al 1998). The improving effect of silica fume at the interface is mainly due to reduction of water film on the aggregate surface because of its pozzolanic action. 
The well-polished aggregate with only mechanical interaction can produce weak bond. The aggregates with good chemical reaction with the cement paste can achieve high bond strength. With porous light weight aggregate surfaces, penetration of cement hydration products into the aggregate increases the interface density due to mechanical interlock. The interface formed on high strength lightweight aggregate with dense outer layer; and on normal weight aggregate appears very similar. On lightweight aggregates with weak and porous outer layer; and also on aggregates without outer layer, the interface seems to be dense and homogeneous. With such aggregate surfaces, the mechanical interlock between the aggregate and the cement paste increases the bond strength (Zhang \& Gjorv 1990). The flaws in the interface may initiate progressive failure. The interface fracture energy varies between 0.01 and $1.17 \mathrm{~J} / \mathrm{m}^{2}$. The van der Wall's forces of attraction are the primary binding forces at the interface (Pye \& Beaudoin 1992). With andesite and dolomite aggregates, the interface energies are $20 \mathrm{~J} / \mathrm{m}^{2}$ and $10 \mathrm{~J} / \mathrm{m}^{2}$ respectively.

The interface could be explained through the structure of Calcium-Silicate-Hydrates (CSH), which is of nanometer to micrometer scale and bonded through the van der Wall's forces. The water between the particles plays very significant role (Alexander 1993). A chemical reaction of cement paste with limestone and andesitic aggregates can raise the micro-hardness and can reduce the crack resistance. Such interface exhibits low toughness, and with the addition of silica fume, its toughness increases (Saito \& Kawamura 1986).

The failure of high strength concrete (HSC) members is preceded by a large linear ascending load-displacement response with negligible post-peak displacement with catastrophic failure (Lee \& Buyukozturk 1995). The fine aggregate in mortars increases the cracking resistance due to bridging action. The finer fraction of the aggregate does not produce preferential orientation of $\mathrm{CH}$ crystals. The strong size effect on the interface fracture toughness with brittle failure has been reported (Trende \& Buyukozturk 1998). For the given loading, the critical interface fracture energy release rate, $G_{i}$ increases with the rough surfaces in both mode $I$ and in mixed modes. For the given roughness, the interface fracture energy release rate, $G_{i}$ increases with increase in shear loading. Testing of the wedge-splitting composite specimens of different size shows that there is a non-negligible size effect in the interface ranging from 22.50 to $85 \mathrm{~cm}^{2}$ (Tschegg et al 1996). The interface fracture energy, $\mathrm{G}_{i}$, of the sandstone and the limestone-matrix, ranges between 6 and $18 \mathrm{~N} / \mathrm{m}$ respectively, while the fracture energy of the mortar was $80 \mathrm{~N} / \mathrm{m}$. The resistance of the interface is about $1 / 6^{\text {th }}$ of that of the mortar matrix.

The crack deflection occurs when the interface roughness decreases relatively with the roughness of matrix. The tests on sandwich beams $(152.0 \times 50.8 \times 38.1 \mathrm{~mm})$ under mode I loading reveal that the interface fracture energy increases as the loading phase increases (Lee \& Buyukozturk 1995). This is due to shielding effect at the interface with increasing shear loading. At high-phase angle, the interface crack kinking takes place into the mortar or into the aggregate. Hence, the two modes of failures are distinguished for interface cracking (Vervurt 1997). The presence of aggregate in the mortar matrix lowers the cracking load due to stress concentration effect of the aggregate. The extra energy is required for further crack growth when it reaches the interface. An attempt has been made in this paper to study the interface and its influence on the behaviour of concrete using sandwich, and direct rock-mortar compact specimens under mode I and mode II loading effects.

\section{Research significance}

The stress-strain response in high strength concrete has been observed to be linear up to the peak load due to strong interface formed between different phases of concrete. The behaviour 
of interface appears to be brittle, and hence the LEFM concepts may seem to be applicable to determine its fracture properties. The studies on interface bond strength, interface energy, behaviour of interface, and its influence on stiffness and ductility of concrete are very rarely reported. The interface fracture parameters using double edge-notch sandwich tension specimens with different mortars and surface characteristics of aggregate have been investigated. The size effect in interface in different modes of failure with different notch sizes has been verified.

\section{Experimental program}

\subsection{Materials}

An ordinary Portland cement with $10 \%$ silica fume replacement by weight of cement was used. The chemical properties of cement and silica fume are shown in tables 1 and 2 respectively. The natural river sand passing through $2.36 \mathrm{~mm}$ sieve with a specific gravity of 2.68 was used. Potable water was used. A high range water reducing agent at $5 \mathrm{lit} / \mathrm{m}^{2}$ was used. The interface between the matrix and different aggregate surfaces was prepared using three different mortars. The water-cementitious ratio was 0.40 . The three mortars are designated as CM-I, CM-II and CM-III. The cement-sand ratios are 1:2,1:3 and 1:4 respectively to achieve different strengths. Table 3 shows the mix proportions and properties of the mortars. The compressive strength of mortars was determined on $50 \mathrm{~mm}$ cubes and the tensile strength on split cylinders of $100 \mathrm{~mm}$ diameter. The modulii of elasticity of mortars and granite rock were obtained using the ultrasonic pulse velocity technique.

\subsection{Geometry of test specimens}

Two types of specimen were used as shown in figure 1. The hardened concrete blocks prepared with different aggregate sizes, and granite (rock) aggregate slices with different surface characteristics were prepared. Half of the mould was covered with the pre-fabricated hardened concrete or granite blocks with different surface characteristics. The empty half of the portion of

Table 1. Chemical properties of 43 grade cement.

\begin{tabular}{llcr}
\hline S1. No. & Chemical characteristics & Expressed as & 43 Grade cement \\
\hline 1 & Loss on ignition & $\%$ & 1.40 \\
2 & Insoluble residue & $\%$ & 0.40 \\
3 & Total silica & $\%$ & 21.70 \\
4 & Alumina & $\%$ & 5.00 \\
5 & Ferric oxide & $\%$ & 4.20 \\
6 & Calcium oxide & $\%$ & 63.90 \\
7 & Magnesium oxide & $\%$ & 1.20 \\
8 & Sulfuric anhydride & $\%$ & 1.85 \\
9 & Lime saturation factor & - & 0.90 \\
10 & Alumina modulus & $\%$ & 1.19 \\
11 & Tricalcium silicate & $\%$ & 50.30 \\
12 & Di calcium silicate & $\%$ & 24.30 \\
13 & Tri calcium aluminate & $\%$ & 6.15 \\
14 & Tetra calcium alumino ferrite & & 12.80 \\
\hline
\end{tabular}


Table 2. Chemical composition of silica fume.

\begin{tabular}{ll}
\hline Composition & Result, $\%$ \\
\hline $\mathrm{SiO}_{2}$ & 93.60 \\
$\mathrm{Al}_{2} \mathrm{O}_{3}$ & 0.80 \\
$\mathrm{Fe}_{2} \mathrm{O}_{3}$ & 0.50 \\
$\mathrm{CaO}$ & 1.80 \\
$\mathrm{MgO}$ & 1.10 \\
$\mathrm{Na} O$ & 0.10 \\
$\mathrm{~K}_{2} \mathrm{O}$ & 0.10 \\
$\mathrm{MnO}$ & $\mathrm{BD}$ \\
$\mathrm{TiO}_{2}$ & $\mathrm{BD}$ \\
$\mathrm{H}_{2} \mathrm{O}(-)$ & 0.60 \\
$\mathrm{L.O.I.}$ & 1.0 \\
\hline
\end{tabular}

L.O.I. $=$ Weight loss at $900^{\circ} \mathrm{C}$ (includes $\mathrm{H}_{2} \mathrm{O}(+)$ ), $\mathrm{H}_{2} \mathrm{O}(-)=$ Weight loss at $110^{\circ} \mathrm{C}, \mathrm{BD}=$ below detection

the mould was filled with fresh mortar against granite aggregate or hardened concrete surface to produce different interfaces.

Five different aggregate surfaces were produced to test the specimen in direct tension. These five types of surfaces include; rough, and smooth granite surface, rough, and smooth hardened concrete surfaces, and direct casting surface of hardened concrete. In sandwich composite specimens, a thin slice of aggregate (granite) or hardened concrete with different surface characteristics were embedded in moulds at appropriate location, before fresh mortar was poured into the empty portions on either side of the slice. In this specimen also different surface characteristics of the aggregates or hardened concrete were selected to produce different interfaces. At the junction of the mortar and the aggregate (rock) or hardened concrete, two edge notches were formed using a diamond saw cutter just before testing. The double edge notched compact specimens were then loaded in direct tension normal to the edge notches to fail in mode I. Similar specimens were prepared to test in mode II loading.

\subsection{Preparation of test specimens}

The test specimens were rectangular in plan with length-to-width ratio 2.0 and $80 \mathrm{~mm}$ thick. The actual geometric dimensions were used for calculating various parameters. The rough surface of the aggregate was formed by chiseling with different roughness pattern, and the smooth surfaces were produced by a diamond saw cutter. In this study, rough, smooth, and casting surfaces of the hardened concrete were intentionally prepared. The different types of casting surfaces of

Table 3. Mix proportioning and strength of mortars.

\begin{tabular}{lcccccccc}
\hline Mortar & $\begin{array}{c}\text { C-S } \\
\text { Ratio }\end{array}$ & $\begin{array}{c}\text { W-C } \\
\text { Ratio }\end{array}$ & $\begin{array}{c}\text { SF, \% } \\
\text { mm }\end{array}$ & $\begin{array}{c}\text { Sand size, } \\
\text { mm }\end{array}$ & $\begin{array}{c}\text { Compressive } \\
\text { strength, MPa }\end{array}$ & $\begin{array}{c}\text { Pulse } \\
\text { velocity, km/s }\end{array}$ & $\begin{array}{c}\text { Modulus of } \\
\text { elasticity, MPa }\end{array}$ & $\begin{array}{c}\text { Tensile } \\
\text { strength, MPa }\end{array}$ \\
\hline CM-I & $1: 2$ & 0.40 & 10 & 2.36 & 43.10 & 3.96 & 25000 & 2.31 \\
CM-II & $1: 3$ & 0.40 & 10 & 2.36 & 46.00 & 4.00 & 25540 & 2.38 \\
CM-III & $1: 4$ & 0.40 & 10 & 2.36 & 30.07 & 3.95 & 24820 & 1.33 \\
\hline
\end{tabular}


(a)

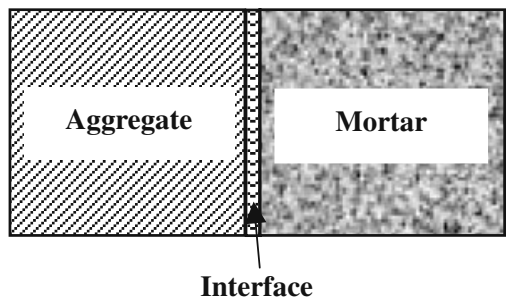

(b)

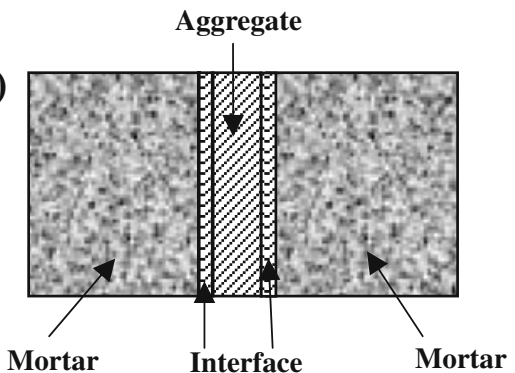

Figure 1. Typical test specimens used in the study. (a) Aggregate and mortar are in direct contact, (b) aggregate is embedded in mortar.

concrete were produced using different sizes of coarse aggregate. Specially fabricated steel grips were used to apply the tensile load in the specimens. The direct shear loading was applied to produce mode II failure. The tension test set-up consists of steel angles welded with steel flats to provide sufficient contact area for gripping the specimen. Nuts and bolts system was designed to fasten the composite specimen along with G-clamps for achieving additional gripping to avoid slipping of the specimen in the grips. To minimize the concentration effects, $3 \mathrm{~mm}$ thick rubber padding was also provided between the test specimen and the loading platens. Different sizes of specimens were produced to understand the size effect in interface.

\subsection{Testing of specimens}

With the procedure mentioned in section 4.3, the interface fracture properties have been studied. The interface was created between mortar matrix and rough hardened high strength concrete $\left(f_{c k}>100 \mathrm{MPa}\right)$ surface. Different sizes of the test specimens have been prepared which resulted in different interface area. The thickness of the composite specimen was $80 \mathrm{~mm}$. However, while calculating various properties the actual existing geometric dimensions were used. Sandwiched composite specimens with mode-I and mode-II loading effects were used. The load was applied gradually up to the peak in increments. At every load increment, the CMOD in mode I was recorded using LVDT mounted by aluminium angles glued at each notch of the mouth. In order to measure the crack mouth sliding in mode II, aluminium angles were glued on either side of the interface. The movement of aggregate strip was monitored by the relative displacement between aggregate and the mortar. The work of fracture is the area under the load vs. CMOD or slip curve. The interface fracture energy was estimated by dividing the work of fracture by the actual failure interface area. The smallest LVDT used in the study could measure a maximum displacement of $\pm 500 \mu \mathrm{m}$ in one set-up, with which it could sense a smallest displacement of $1.0 \mu \mathrm{m}$ during the test. The Load-CMOD variations in granite rock and mortar were observed on TPB and DENCTS respectively. Due to its highly brittle nature of the interface, the variation of CMOD or slip with load could be monitored up to peak load.

\section{Test results and discussion}

\subsection{Mode I fracture parameters}

5.1a Load-CMOD response: The load versus crack mouth opening displacement responses were measured in all the test specimens. Figure 2 shows a typical load- crack mouth opening 


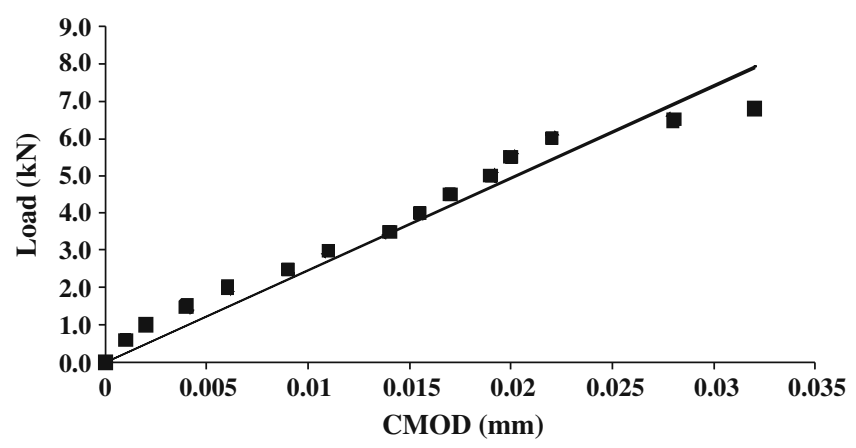

Figure 2. Load vs. CMOD at the interface under mode I loading.

displacement, CMOD response obtained at the interface in mode I loading. The load vs. CMOD response could be monitored only up to the peak load because the interface was brittle causing sudden failure. The load-CMOD response at the interface is linear up to the peak load. This response could reveal that the interface in HSC is brittle, which is different from the expected failure in cement pastes and mortars. This response in the interface enables to make use of the classical LEFM concepts to characterize the failure of interface in concrete. Similar observations have been reported (Lee \& Buyukozturk 1995), where the failure of interface was preceded by a linear ascending response with no post-peak resistance showing catastrophic failure. At every load increment, CMOD was measured using the linear variable differential transducers (LVDT). The critical CMOD in mortar and rock are shown in table 4. The values of the measured CMOD at the interface in sandwich composite specimens are shown in tables 5 and 6 . With smooth concrete surface, the measured CMOD was $50 \mu \mathrm{m}$, whereas in casting surface of hardened concrete showed only $9 \mu \mathrm{m}$. The observed CMOD with rough granite aggregate ranges between $11 \mu \mathrm{m}$ and $24 \mu \mathrm{m}$. Due to brittle nature, the interface fracture properties could be characterized using LEFM.

5.1b Tensile strength of interface: The interface area formed with mortar in direct contact with the aggregate surface has been observed to vary between 3000 and $6720 \mathrm{~mm}^{2}$. The tensile stress

Table 4. Fracture properties of mortar and rock specimens.

\begin{tabular}{|c|c|c|}
\hline Material & Mortar & Rock \\
\hline Tensile strength, MPa & 1.94 & 9.05 \\
\hline Modulus of elasticity, $\mathrm{MPa}$ & 24900 & 39210 \\
\hline Type of specimen & DENCTS & TPBS \\
\hline Area of ligament, $\mathrm{mm}^{2}$ & 8300 & 5469 \\
\hline Failure load, Kn & 16.10 & 5.85 \\
\hline Work of fracture, $\mathrm{N}-\mathrm{m}$ & 0.60 & 0.42 \\
\hline Fracture energy, N/m & 72.30 & 76.80 \\
\hline Fracture toughness, $\mathrm{MPa} \sqrt{ } \mathrm{m}$ & 1.34 & 1.74 \\
\hline Characteristic length, $\mathrm{mm}$ & 478 & 36.80 \\
\hline Stiffness, $\mathrm{kN} / \mathrm{mm}$ & 64.285 & 240 \\
\hline $\mathrm{CMOD}_{\mathrm{c}}, \mu \mathrm{m}$ & 9 & 12 \\
\hline Ductility factor, $\left(\mathrm{G}_{\mathrm{i}} / \sigma\right)\left(\left(\mathrm{J} / \mathrm{m}^{2}\right) / \mathrm{kN}\right)$ & 37.27 & 8.49 \\
\hline
\end{tabular}




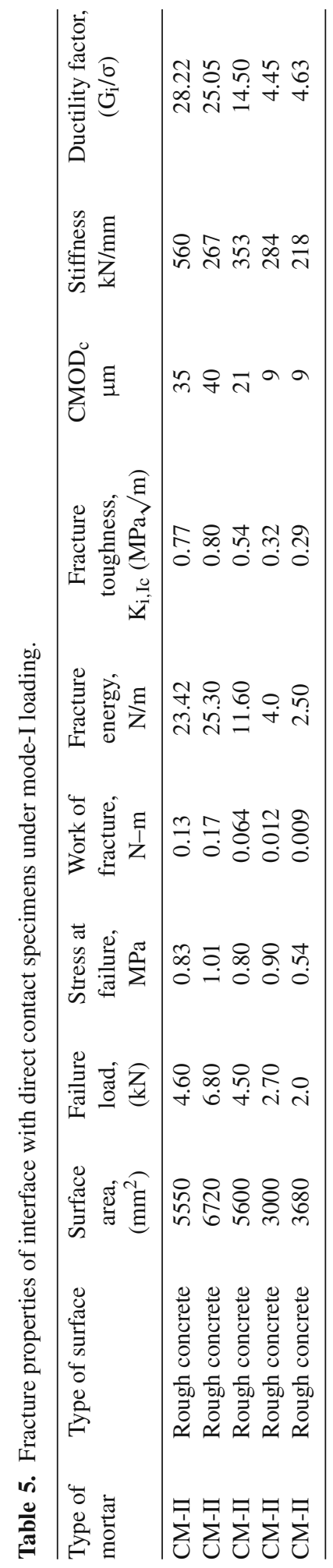




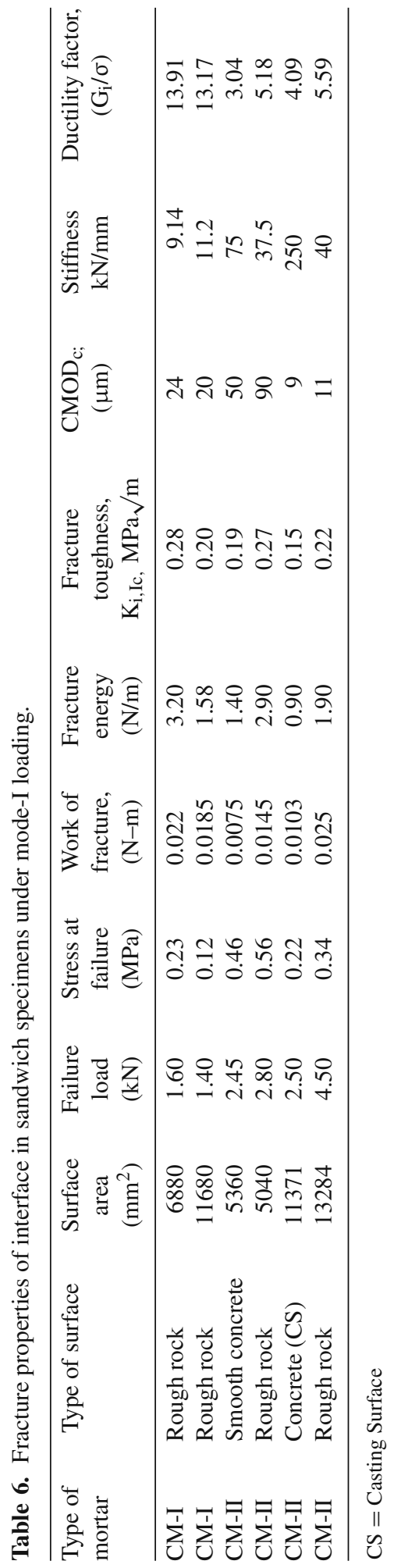


at the interface with rough concrete surface ranges between 0.54 and $1.01 \mathrm{MPa}$. This is about $1 / 4$ th to $1 / 2$ nd of the tensile strength of mortar, as shown in table 4 . Tables 5 and 6 show the tensile strength of interface. The modulus of rupture of the granite aggregate was about 20 to 10 times greater than the tensile strength of the interface. In sandwich composite specimens, the normal stress at the interface ranges between 0.12 and $0.56 \mathrm{MPa}$, which is about 1/16th to $1 / 3.5$ th of that of the mortar. The strength of the interface with smooth hardened concrete surface is $0.46 \mathrm{MPa}$, which is relatively high compared with that of rough rock surface. The strength of the interface in CM-II is significantly high with rough concrete surface than that of rough granite aggregate. The strength of the interface with CM-I mortar is relatively low.

5.1c Mode I fracture energy of interface: The work of fracture, $\mathrm{W}_{\mathrm{F}}$, is the area under the loadCMOD response up to the critical crack mouth opening displacement, $\mathrm{CMOD}_{\mathrm{c}}$. The fracture energy, $G_{i}$ is the work of fracture per unit crack surface area. $G_{i, I}$ is determined by the following relationship

$$
G_{i, I}=W_{F} / A_{l i g} .
$$

The observations are shown in tables 5 and 6 under mode I loading. The crack mouth opening displacement, CMOD at the interface with mortar CM-II and rough aggregate surface ranges between $9 \mu \mathrm{m}$ and $40 \mu \mathrm{m}$. The work of fracture has been found to vary between 0.009 and $0.17 \mathrm{~J}$. The fracture energy of the mortar and the granite aggregate were $72.30 \mathrm{~J} / \mathrm{m}^{2}$, and $76.80 \mathrm{~J} / \mathrm{m}^{2}$ respectively, as shown in table 4 . The mode-I fracture energy of the interface has been found to vary between 2.5 and $25.30 \mathrm{~J} / \mathrm{m}^{2}$, which is in the range of $1 / 25$ th to $1 / 3 \mathrm{rd}$ of that of the mortar or aggregate. The rough surface of the hardened concrete containing large size aggregate exhibited traces of significant pulling out of the aggregate. The fracture surface of the concrete was tortuous and porous. With such surfaces, the fracture energy of the interface increases significantly due to the improved mechanical interlock. Further, the addition of silica fume also increases the bond strength. Such a trend has been reported by Alexander (1993), in which the type of aggregate surface had significant influence on the interface properties. The interface fracture energy has been observed to range between $20 \mathrm{~J} / \mathrm{m}^{2}$ and $10 \mathrm{~J} / \mathrm{m}^{2}$ depending on the shape of the aggregate. A strong size effect has been noticed on the interface fracture toughness showing brittle interfaces in cementitious materials (Trende \& Buyukozturk 1998). The crack was observed to propagate along the interface. This reveals that the interface seems to be very brittle, and vulnerable for the crack to propagate. The fracture energy of the interface with the rough aggregate surface ranges between $1.58 \mathrm{~J} / \mathrm{m}^{2}$ and $3.2 \mathrm{~J} / \mathrm{m}^{2}$. In the sandwich composite specimens, there exists only a negligible size effect (Tschegg et al 1996). $\mathrm{G}_{\mathrm{i}}$ values with the interface formed between sandstone and matrix, and between limestone and matrix were reported to range between $6 \mathrm{~J}$ and $18 \mathrm{~J}$, although the specific fracture energy of the matrix were about $80 \mathrm{~J}$. The interface with the smooth and casting surfaces of the hardened concrete exhibits somewhat lower fracture energy than that of the rough granite aggregate. It was possible to expect a chemical reaction between the aggregate in concrete and the silica fume matrix, resulting in high fracture energy with smooth hardened concrete surface. The interaction between cement paste and aggregate surface lowers both the toughness and the cracking resistance at the interface (Saito \& Kawamura 1986). On casting surface of hardened concrete, cement paste could penetrate into the voids to improve the mechanical interlock.

The type of interface also depends on the microstructure of the aggregate. With the porous aggregate surface, the hydration products penetrate into the pores improving the mechanical interlock (Zhang \& Gjorv 1990). The fracture energy of the interface with the casting surface 
of the hardened concrete has been found to be $0.90 \mathrm{~J} / \mathrm{m}^{2}$, while it is $1.40 \mathrm{~J} / \mathrm{m}^{2}$ with the smooth hardened concrete surface. Similar observations have been made by the earlier workers (Pye \& Beaudoin 1992). The resistance of the interface against the crack propagation is only 1/6th of that of the matrix. The aggregate in the mortar matrix decreases the cracking load (Vervurt 1997) due to the stress concentration effect of the coarse aggregate.

5.1d Mode I fracture toughness of interface: The stress intensity factor at the peak load is known as the critical stress intensity factor or the fracture toughness. In this study, only the critical stress intensity factors observed in the interface are reported in tables 5 and 6 . The fracture toughness of the aggregate and the mortar has been observed as $1.74 \mathrm{MPa}[\mathrm{m}]^{1 / 2}$ and 1.34 $\mathrm{MPa}[\mathrm{m}]^{1 / 2}$ respectively as shown in table 4 . The granite aggregate looks relatively ductile in comparison with the mortar. The mortar used in this study is stronger than the aggregate. The fracture toughness of interface under mode I loading with rough hardened concrete surface against mortar has been observed to vary between 0.29 and $0.80 \mathrm{MPa}[\mathrm{m}]^{1 / 2}$. In the sandwich specimens under mode I loading, the fracture toughness has been found to vary between 0.20 and $0.28 \mathrm{MPa}[\mathrm{m}]^{1 / 2}$ with the rough granite aggregate surface. In the interface formed with smooth, and hardened concrete cast surface, the fracture toughness under mode I loading have been observed to be 0.15 and $0.19 \mathrm{MPa}[\mathrm{m}]^{1 / 2}$ respectively. As the mechanical interlocking at the interface increases, the fracture toughness increases.

5.1e Effect of interface on stiffness of concrete: The stiffness of the composite sandwich specimens with different aggregate surface is shown in table 6. The slope of the linear load-CMOD response is the stiffness, ' $\mathrm{k}$ ' in $\mathrm{N} / \mathrm{mm}$. The stiffness of the specimen is proportional to the modulus of elasticity of the material. The stiffness of the mortar and granite aggregate were found to vary between 64.29 and $240 \mathrm{kN} / \mathrm{mm}$ respectively. The stiffness of composite specimen was observed to be high as shown in tables 5 and 6 . The stiffness with CM-II mortar against the rough concrete surface ranges between 218 and $560 \mathrm{kN} / \mathrm{mm}$. Low stiffness values have been observed in sandwich composite specimens. The rough granite aggregate with CM-II mortar exhibited relatively high stiffness than that of CM-I mortar. The stiffness of composite specimen with CM-I mortar is $10 \mathrm{kN} / \mathrm{mm}$, whereas the stiffness with CM-II mortar is significantly high. The stiffness of composite specimen with cast concrete surface is $250 \mathrm{kN} / \mathrm{mm}$. The stiffness of composite specimen with rough aggregate surface is $40 \mathrm{kN} / \mathrm{mm}$. The stiffness of composite specimen with smooth hardened concrete surface is $75 \mathrm{kN} / \mathrm{mm}$. This indicates that the interface varies with different aggregate surfaces. In composite specimens with rough aggregate surface against strong mortar produced very high stiffness and high load carrying capacity. Therefore, the concrete produced with rough aggregate surface characteristics using strong mortars showed very high stiffness and brittleness.

5.1f Effect of interface on ductility of concrete: Ductility is defined as the ratio of the fracture energy to the peak stress $\left(\mathrm{G}_{\mathrm{i}} / \sigma\right)$. The ductility of the specimens increases as the roughness of the aggregate surface increases as shown in tables 5 and 6 . With smooth aggregate surface the ductility of composite specimen has been observed to be decreased. The ductility of specimens with mortar matrix against the hardened concrete interface has been observed to be higher than that of the rough aggregate. In case of interface with mortar matrix and rough concrete, the ductility of composite specimens varies between 4.45 and $28.22(\mathrm{~N} / \mathrm{m}) / \mathrm{MPa}$, whereas in sandwich 
composite specimens, it varies from 3.04 to $13.91(\mathrm{~N} / \mathrm{m}) / \mathrm{MPa}$. In the specimens with aggregate in direct contact with mortar or aggregate slice embedded in mortar, the rough aggregate surfaces resulted in higher ductility. The smooth concrete surface had shown less ductility i.e., more brittleness.

In sandwich composite specimens, the ductility has been observed to decrease as the interface surface area increases. With strong interface, the ductility of composite specimen decreases with increasing the interface area. In strong mortars with silica fume, very strong interface has been formed. This results in transgranular type of failure in concrete. Hence, the strong interface can lead to brittle composites, which exhibit linear response. This is also due to minimizing the mismatch between the stiffness of aggregate, mortar and the interface. The interface behaves linearly up to peak load, which is followed by catastrophic failure.

\subsection{Mode II fracture parameters}

5.2a Slip in interface: The slip (deformation under shear loading) at the interface under direct shear has been monitored. Mortar CM-II is stronger than mortars CM-I and CM-III. The fracture properties of interface in mode II are shown in table 7. The slip in the interface at failure has been observed to range between $4 \mu \mathrm{m}$ and $9 \mu \mathrm{m}$ in CM-II mortar, whereas in CM-I and CM-III mortars, the slip at the interface has been observed to be about $10 \mu \mathrm{m}$. The load-slip response at the interface has been observed to be linear up to the peak load. Beyond the peak load, the composite specimens exhibit catastrophic failure. The slip at the interface in CM-II mortar with rough rock surface ranges between $3 \mu \mathrm{m}$ and $17 \mu \mathrm{m}$, as shown in table 7 . The interface has been observed to be stiff and strong in rich mortars. The slip in such interfaces seems to be relatively low at the peak load. A typical load-slip response under mode II loading is shown in figure 3. Similar observations have been reported earlier also, where the failure at the interface was preceded by linear ascending response followed by steep post-peak response (Lee \& Buyukozturk 1995).

5.2b Shear strength of interface: The strength of the interface against direct shear with different mortars has been observed to range between 0.79 and $2.79 \mathrm{MPa}$. The shear strengths of interface are shown in table 7. The shear strengths of interface with CM-II mortar against smooth hardened concrete surface have been observed to be 2.13 and $2.61 \mathrm{MPa}$. The shear strengths have been observed to vary between 2.24 and $2.79 \mathrm{MPa}$ with rough granite aggregate against mortar CM-II. The shear strength of interface was less than $1.66 \mathrm{MPa}$ with rough granite aggregate with mortar CM-III. With mortar CM-I, the shear strength has been found to be relatively low. On smooth hardened concrete surface, the chemical reaction between the aggregate in hardened concrete and the mortar due to pozzolanic reaction of silica fume might have occurred. The shear strength of the interface increases as the roughness of aggregate increases. Further, the shear strength also increases as the inclination of interface increases due to shielding effect of aggregate.

5.2c Fracture energy of interface: The work of fracture, $\mathrm{W}_{\mathrm{F}}$, is the area under the load-CMOD response up to the critical crack mouth opening displacement, $\mathrm{CMOD}_{\mathrm{c}}$. The fracture energy, $\mathrm{G}_{i, I I}$ is the work of fracture per unit crack surface area. $\mathrm{G}_{i, I I}$ is determined by the following relationship

$$
G_{i, I I}=W_{F} / A_{\text {lig }} \text {. }
$$

The fracture energy of the interface under mode-II loading, $\mathrm{G}_{i, I I}$ increases as the roughness of the aggregate surface increases. When the orientation of the interface surface increases, the 


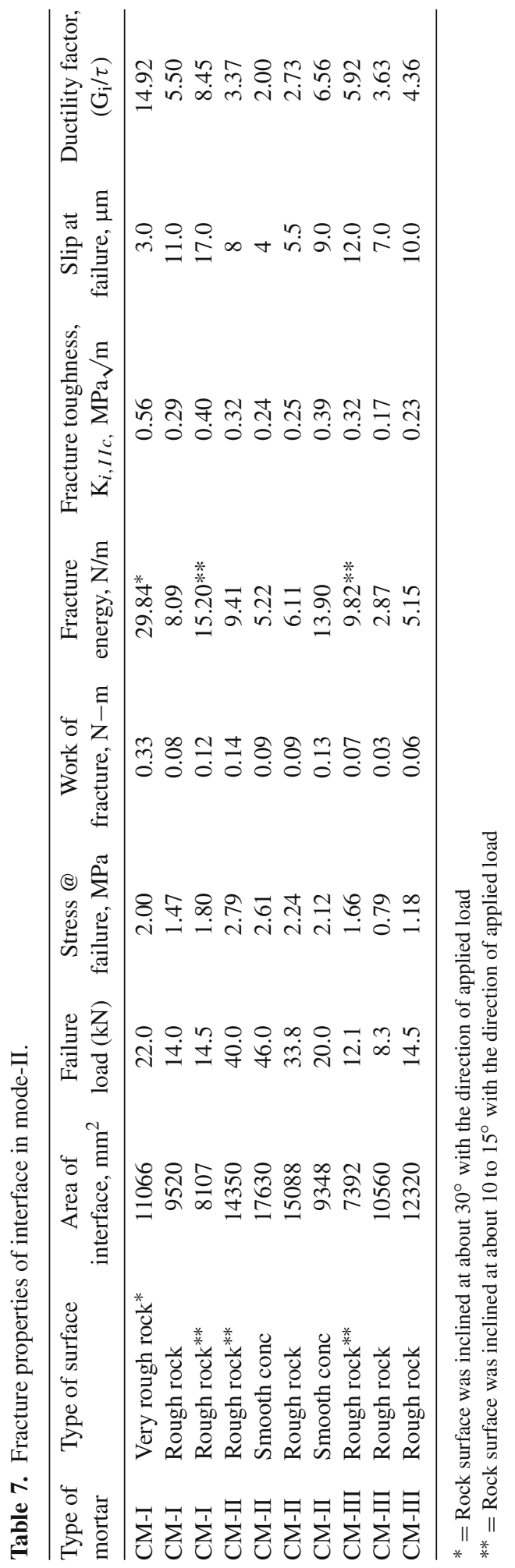




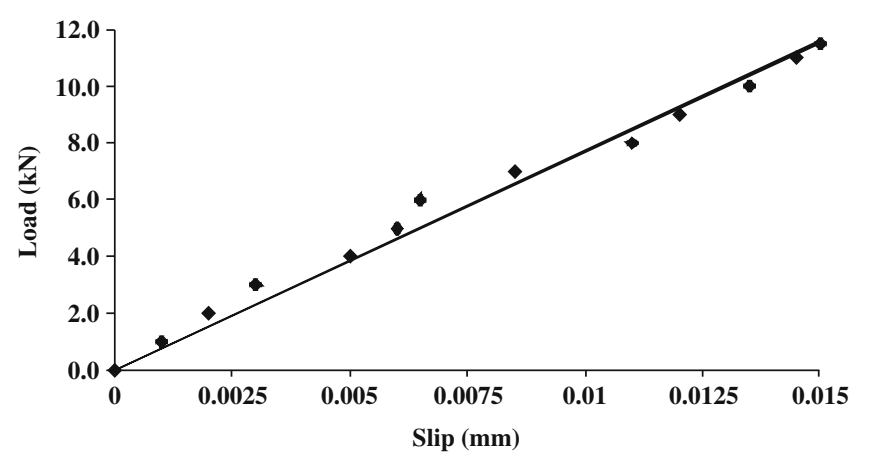

Figure 3. Load-slip response under mode II loading.

mode-II fracture energy increases significantly. The increase in the orientation of the interface leads to mixed mode (mode-I and II) failure. The inclination of the granite aggregate surface was varied between 10 and $30^{\circ}$ with the direction of loading. The fracture energy of interface in mode II loading in various cases is shown in table 7 . The fracture energy of the interface with rough granite aggregate has been observed to vary between 2.87 and $8.09 \mathrm{~J} / \mathrm{m}^{2}$. When the rock surface was inclined at 10 to $15^{\circ}$ with the direction of loading, the fracture energy has been found to vary between 9.41 and $15.20 \mathrm{~J} / \mathrm{m}^{2}$. At an inclination of $30^{\circ}$, the fracture energy was observed to be $29.84 \mathrm{~J} / \mathrm{m}^{2}$. This indicates that the fracture energy of interface in direct shear increases as the orientation of the aggregate surface increases. Similar observations have been reported by the earlier studies (Lee \& Buyukozturk 1995). A strong size effect on interface toughness with brittle failure was reported (Trende \& Buyukozturk 1998). With high-phase angles, the interface crack kinking into the mortar or aggregate has been observed.

5.2d Fracture toughness of interface: The stress intensity factor at the peak load is known as the critical stress intensity factor or the fracture toughness. In this study, only the critical stress intensity factors observed in the interface are reported. Under mode II loading, as shown in table 7 , the fracture toughness of the interface with smooth hardened concrete surface has been found to vary between 0.24 and $0.39 \mathrm{MPa}[\mathrm{m}]^{1 / 2}$. The fracture toughness with the rough granite aggregate surface ranges between 0.17 and $0.56 \mathrm{MPa}[\mathrm{m}]^{1 / 2}$. The lower value has been observed with less tortuous surface, and the higher value with rough aggregate surface.

5.2e Effect of interface on ductility of concrete: Ductility is defined as the ratio of the fracture energy to the shear strength $\left(\mathrm{G}_{\mathrm{i}} / \tau\right)$. In table 7 , the ductility of the specimen under mode II loading is shown with different aggregate surfaces and mortars. The ductility of the composite specimen increases as the roughness of the aggregate surface increases. The smooth concrete surface decreases the ductility of the composite specimens. The behaviour of such concretes is brittle with catastrophic failure. In composite specimens under mode-II loading, the ductility of specimen decreases with increase in interface area. The ductility of specimen has been observed to vary between 2.0 and $14.92(\mathrm{~N} / \mathrm{m}) / \mathrm{MPa}$. The higher value corresponds to very rough aggregate surface and the smaller value corresponds to smooth concrete surface. 


\section{Conclusions}

The following conclusions can be drawn from the experimental observations:

(i) The load-CMOD response in the interface has been observed to be linear up to the peak load followed by catastrophic failure. This behaviour shows that the application of LEFM concepts is possible. Low CMOD has been noticed at the interface with smooth hardened concrete.

(ii) The interface has been found to be weaker than the mortar or aggregate. The strength of the interface is about (1/16th to 1/3.5th) of that of the mortar. The strength and the fracture energy of interface increases with the addition of silica fume.

(iii) The shear strength increases as the roughness, and the inclination of the interface increase. The reaction between cement and aggregate interface results in high shear strength.

(iv) The fracture energy of interface increases as the roughness of aggregate increases, while it is further increased with inclination of the interface under mode-II loading.

(v) Ductility of composite specimens increases as the roughness of aggregate surface, and the area of interface increase.

\section{Notation}

$a_{0} \quad$ Total notch depth in the composite specimen, $\mathrm{mm}$

$A_{\text {lig }} \quad$ Total area of the ligament, $\mathrm{mm}^{2}$

$b \quad$ Thickness of the specimen, $\mathrm{mm}$

C Compliance, $\mathrm{mm} / \mathrm{N}$

$C M O D$ Crack mouth opening displacement, $\mathrm{mm}$

$C M O D_{c}$ Critical crack mouth opening displacement, $\mathrm{mm}$

CS Casting surface

$d \quad$ Depth of the specimen, $\mathrm{mm}$

$G_{F} \quad$ Fracture energy, $\mathrm{J} / \mathrm{m}^{2}$

$G_{i} \quad$ Interface fracture energy, $\mathrm{J} / \mathrm{m}^{2}$

$k \quad$ Stiffness of the composite specimen, $\mathrm{kN} / \mathrm{m}$

Mode I Loading type which opens the crack

$P \quad$ Ultimate load, $\mathrm{kN}$

$W_{F} \quad$ Work of fracture, $\mathrm{J}=\mathrm{N}-\mathrm{m}$

\section{References}

Alexander M G 1993 'Two experimental techniques for studying the effects of the interfacial zone between cement paste and rock', Cement and Concrete Res. 23: 567-575

Bentur A, Cohen M D 1987 'Effect of condensed silica fume on the microstructure of the interfacial zone in Portland cement mortars', J. Am. Cer. Soc. 70(10): 738-743

Cheng-yi H, Feldman R F 1985 'Influence of silica fume on the micro-structural development in cement mortars', Cement and Concrete Res. 15: 285-294

Cohen M D, Goldman A, Chen W F 1994 'The role of silica fume in mortar: Transition zone versus bulk paste modification', Cement and Concrete Res. 24: 95-98 
Feldman R F 1986 'The effect of sand/cement ratio and silica fume on the microstructure of mortars', Cement and Concrete Res. 16: 31-39.

Larbi J A, Bijen J M J M 1990 'Orientation of CH at the PC paste -aggregate interface in mortars in the presence of SF: A contribution', Cement and Concrete Res. 20: 461-470

Lee K M, Buyukozturk O 1995 'Fracture toughness of mortar-aggregate interfaces in high-strength concrete', ACI Structural Journal 92: 634-642

Monterio P J M, Maso J C, Ollivier J P 1985 'The aggregate-mortar interface', Cement and Concrete Res. 15: 953-958

Ping X, Beaudoin J J 1992 'Modification of transition zone microstructure- silica fume coating of aggregate surfaces', Cement and Concrete Res. 22: 597-604

Pye G B, Beaudoin J J 1992 'An energy approach to bond strength determinations in cement systems', Cement and Concrete Res. 22: 551-558

Saito M, Kawamura M 1986 'Resistance of the cement-aggregate interfacial zone to propagation of cracks', Cement and Concrete Res. 16: 653-661

Toutanji H A, Liu L, El-korchi T 1999 'The role of silica fume in the direct tensile strength of cement-based materials', Materials and Structures 32: 203-209

Trende U, Buyukozturk O 1998 'Size effect and influence of aggregate roughness in interface fracture of concrete composites', ACI Mater. Journal 95(4): 331-338

Tschegg E K, Rotter H M, Roelfstra P E, Bourgund U, Jussel P 1996 'Fracture mechanical behavior of aggregate-cement matrix interfaces', J. Mater. in Civil Eng. 7(4): 199-203

Vervurt A H J M 1997 'Interface Fracture in Concrete', Ph.D. thesis at Delft University of Technology, Netherlands

Winslow D, Liu D 1990 'The pore structure of paste in concrete', Cement and Concrete Res. 20: 227-235

Wong Y L, Lam L, Poon CS, Zhou FP 1999 'Properties of fly ash-modified cement mortar-aggregate interfaces', Cement and Concrete Res. 29: 1905-1913

Yang S, Zhongzi X, Mingshu T 1998 'Improving the structure of the interfacial zone and its influence on the long-term behavior of mortars', Mater. Structures 31: 230-234

Zhang M H, Gjorv O E 1990 'Microstructure of the interfacial zone between lightweight aggregate and cement paste', Cement and Concrete Res. 20: 610-618

Zimbelmann R 1987 'A method for strengthening the bond between cement paste and aggregates', Cement and Concrete Res. 17: 651-660 